\title{
Análise colorimétrica e espectroscópica do muco de caracóis terrestres Achatina sp alimentados com ração diferenciada
}

\author{
Adriana Tarlá Lorenzi ${ }^{1}$, Maria de Fátima Martins ${ }^{2}$ \\ ${ }^{1}$ Programa de Pós-graduação em Medicina Veterinária pela FMVZ - USP/Pirassununga, SP. \\ ${ }^{2}$ FMVZ - USP/Pirassununga, SP.

\begin{abstract}
RESUMO - Foram estudados os efeitos da adição de plantas medicinais de princípios cicatrizantes (Centelha asiática, Papaína e Confrei) na ração controle de caracóis terrestres, para se avaliar a interferência destas plantas na composição do muco glicoprotéico. Foram utilizados 80 caracóis terrestres Achatina sp, baseados em um peso homogêneo (49 e 40 g e idade média de 10 e 19 meses para Achatina fulica e Achatina monochromatica, respectivamente). Os animais foram distribuídos aleatoriamente em oito grupos experimentais: controle Achatina fulica (FC) e Achatina monochromatica (MC), centelha asiática Achatina fulica (FCe) e Achatina monochromatica (MCe), papaína Achatina fulica (FPa) e Achatina monochromatica (MPa) e confrei Achatina fulica (FCo) e Achatina monochromatica (MCo). Água e ração foram fornecidos ad libitum. Ao final de 150 dias de tratamento, os animais foram submetidos à técnica de extração do muco glicoprotéico, por meio do estímulo manual da glândula podal, responsável pela secreção deste muco. Esta metodologia considerou o bem-estar dos animais, uma vez que os mesmos não foram sacrificados e retornaram ao seu sistema de criação. Os mucos foram analisados por meio de testes colorimétricos e espectroscópicos, que constataram alterações semelhantes, porém apresentaram variação significativa em sua composição glicoprotéica.
\end{abstract}

Palavras-chave: Achatina fulica, escargots, espectroscopia infravermelho, espectroscopia Raman, muco, plantas medicinais

\section{Colorimetric and spectroscopic analysis of mucus of Achatina sp terrestrial snails fed in differentiated diet}

\begin{abstract}
The effects of adding medicinal plants with healing properties (Centelha asiatica, Papaína and Confrei) in the control diet of land snails were studied to evaluate the effect of these plants on the mucus glicoproteic composition. Eighty Achatina sp snails, based on a homogeneous weight (49 and $40 \mathrm{~g}$ and averaging 10 and 19 months of age for Achatina fulica and Achatina monochromatica, respectively). The animals were randomly allotted to eight experimental groups: Achatina fulica (FC) and Achatina monochromatica (MC) control, Asian Achatina fulica (FCe) and Achatina monochromatica (MCe) centelha, Achatina fulica (FPa) and Achatina monochromatica (MPa) papaína and Achatina fulica (FCo) and Achatina monochromatica (MCo) confrei. Ration and water were fed ad libitum. At the end of 150 days of treatment, the animals were submitted to the technique for extraction of mucus glicoproteic by manual stimulation of podal gland, responsible for the secretion of this mucus. This methodology considered the well-being of the animals since they were not slaughtered but returned to their creation system. The mucus was analyzed by means of color and spectroscopic tests, that indicated similar changes, but showed significant variation in their glicoproteic composition.
\end{abstract}

Key Words: Achatina fulica, infrared spectroscopy, medicinals plants, mucus, Raman spectroscopy, scargots

\section{Introdução}

Os caracóis terrestres pertencentes às famílias Achatinidae (África) e Helicidae (Europa) são típicos de regiões tropicais e subtropicais, graças a sua capacidade de adaptação nestes climas, o que torna o Brasil um país com grande potencialidade para a helicicultura tropical extensiva. Os caracóis Achatina sp foram introduzidos no Brasil, em
1988, por criadores consideravam a criação destes animais uma alternativa economicamente viável, pois possuem rápido e intenso processo reprodutivo; assim, as matrizes foram propagadas durante os cursos de helicicultura. No entanto, os consumidores não apreciaram o sabor, a textura e o aspecto da carne deste caracol. A criação destes animais tornou-se inviável aos proprietários, que, devido à rápida proliferação destes animais, passaram a ter gastos excessivos 
e, aliados ao desconhecimento da biologia dos caracóis, jogaram suas criações na natureza de forma inconseqüente, pois, adaptados ao clima brasileiro, os animais não encontraram dificuldades para manter seu ciclo reprodutivo. Diante disso, o Ibama proibiu a comercialização e criação destes animais para fins de consumo, permitindo apenas a pesquisa. Além disso, os caracóis Achatina sp produzem uma substância mucoglicoprotéica composta por uma mistura de materiais provenientes de diversas glândulas, denominadas Achacin, e um muco - um fluido viscoelástico resultante da mistura da secreção de várias glândulas - que possui diversas funções, como veículo de transporte de partículas da superfície ciliada, secreção de produtos, transferência de água e eletrólitos através da epiderme e auxílio na locomoção (Iguchi et al., 1982). A principal função da secreção glicoprotêica envolve a proteção do corpo do animal contra desidratação (Sírio, 2005). Com base em uma associação que propiciasse novos conhecimentos e perspectivas para o estudo deste muco secretado por caracóis Achatina sp, foram utilizadas plantas com finalidades cicatrizantes definidas como confrei, papaína e centelha asiática nas rações ofertadas aos animais. Os métodos colorimétricos são utilizados para determinação quantitativa de açúcares e proteínas presentes em determinada amostra (Dubois et al., 1956). As técnicas de espectroscopia de infravermelho e Raman são as mais comuns para a identificação de compostos orgânicos e inorgânicos, constituindo uma inovação na análise do muco de gastrópodes (Skingsley et al., 2000). As metodologias escolhidas envolvem sensibilidade, estabilidade, simplicidade e rapidez e fornecem dados reproduzíveis.

Objetivou-se com esta pesquisa avaliar, por intermédio do estudo colorimétrico e espectroscópico do muco de caracóis terrestres Achatina sp alimentados com ração adicionada de plantas medicinais, a otimização da composição deste muco para a aceleração do processo cicatricial em animais, a ser desenvolvido em novas pesquisas.

\section{Material e Métodos}

Os caracóis terrestres Achatina sp eram procedentes do Heliciário Experimental Prof ${ }^{a} \operatorname{Dr}^{\mathrm{a}}$ Lor Cury da Faculdade de Medicina Veterinária, da Universidade de São Paulo, Campus Pirassununga. Selecionaram-se 80 caracóis: 40 animais da espécie Achatina fulica e 40 da espécie Achatina monochromatica, com peso e idade médios de 49 e 40 g e de 10 e 19 meses, respectivamente. Os animais foram acondicionados em caixas de madeira (35 cm largura x $30 \mathrm{~cm}$ altura x $60 \mathrm{~cm}$ comprimento), com piso de terra, adicionado de carbonato de cálcio (para fornecer cálcio necessário para o fortalecimento da concha), e densidade populacional de dez exemplares, sendo as caixas aspergidas com água diariamente, para manter a umidade, garantindo o bem-estar destes moluscos. Os animais selecionados foram separados aleatoriamente em oito grupos experimentais, de modo que cada um se referiu a determinado tipo de ração ofertada aos animais, formando quatro grupos experimentais para cada espécie, constituído de 10 animais cada: Controle: Achatina fulica (FC) e Achatina monochromatica (MC); Centelha Asiática: Achatina fulica (FCe) e Achatina monochromatica (MCe); Papaína: Achatina fulica (FPa) e Achatina monochromatica (MPa); e Confrei: Achatina fulica (FCo) e Achatina monochromatica (MCo). A ração desenvolvida para os grupos experimentais foi formulada de acordo com a ração controle (Pacheco \& Martins, 1996), à qual se adicionaram, separadamente, extrato seco em pó das plantas medicinais centelha asiática, confrei e papaína, divididos para cada grupo experimental. A ração controle administrada aos animais durante todo o experimento foi constituída de fubá de milho (57\%), farelo de trigo (13\%), farelo de soja (10\%) e carbonato de cálcio (20\%). Adicionaram-se, separadamente, $100 \mathrm{~g}$ de extrato seco em pó de plantas medicinais a cada $1 \mathrm{~kg}$ de ração controle (10\% de extrato seco), de modo que cada grupo pertencia a um tipo de extrato seco: centelha asiática, papaína e confrei. Estes extratos secos atuaram como aditivo na ração dos animais, para avaliação da contribuição positiva ou negativa em relação à produção de açúcares e proteínas presentes no muco destes caracóis, além do ganho de peso e da preferência alimentar, contribuindo para estudos da área de nutrição animal. As rações foram analisadas bromatologicamente (matéria seca - MS, proteína bruta - PB, extrato etéreo - EE, fibra bruta - FB, cinzas, cálcio, fósforo), conforme métodos descritos em AOAC (1995), no Laboratório de Bromatologia do Departamento de Nutrição e Produção Animal da FMVZ/ USP/Pirassununga.

Os animais foram alimentados com água e ração ad libitum, previamente preparada, de acordo com

Tabela 1 - Composição bromatológica das rações experimentais*

\begin{tabular}{lcrrr}
\hline Ração (\% MS) & Controle & Centelha & Papaína & Confrei \\
\hline MS (\%) & 91,07 & 91,17 & 91,74 & 90,90 \\
MM (\%) & 21,72 & 22,56 & 19,03 & 22,01 \\
EE (\%) & 3,51 & 3,08 & 2,98 & 3,07 \\
FB (\%) & 2,71 & 3,10 & 2,35 & 2,98 \\
PB (\%) & 13,00 & 13,71 & 13,59 & 13,59 \\
Ca (\%) & 6,56 & 6,41 & 6,15 & 6,29 \\
P (\%) & 0,43 & 0,38 & 0,39 & 0,41 \\
\hline
\end{tabular}

* Análises realizadas no laboratório de Bromatologia, FMVZ/USP, Pirassununga. 
especificações de Pacheco \& Martins (1996). Os animais foram pesados ao primeiro dia do experimento e novamente a cada 30 dias, perfazendo um total 150 dias.

O muco dos caracóis das espécies Achatina fulica e Achatina monochromatica foi coletado por meio de estímulo da glândula podal (Martins et al., 2003) em cada animal, segundo a divisão dos grupos experimentais, obtendo-se, então, oito amostras de muco de caracóis terrestres. A metodologia adotada para a extração do muco considerou os conceitos de bem-estar, uma vez que se utilizou o estímulo manual das glândulas podais, o que não ofereceu risco aos animais, de forma que os mesmos retornaram ao sistema de criação executado anteriormente. Foi coletado um volume de muco bruto para cada grupo experimental de $60,80,40,90,30,40,30 \mathrm{e} 30 \mathrm{~mL}$, para os grupos FC, FCe, FPa, FCo, MC, MCe, MPa e MCo, respectivamente.

As análises colorimétricas dos mucos coletados dos caracóis foram realizadas no Laboratório de Bioquímica da Faculdade de Ciências Farmacêuticas da USP de Ribeirão Preto, onde se realizaram as dosagens a partir dos mucos brutos de Achatina fulica e de Achatina monochromatica. Os mucos de cada grupo experimental foram diluídos em água Milli-Q, em tubo de ensaio, obedecendo à diluição de 1:5 para o muco bruto de Achatina fulica e de 1:10 para o muco bruto de Achatina monochromatica. Em seguida, estas soluções foram novamente diluídas, em razão da alta concentração de açúcares: diluição de 1:5 para a solução do muco de Achatina fulica e também para a solução do muco de Achatina monochromatica. A partir da segunda diluição, foram realizadas as dosagens de açúcares totais por colorimetria. A dosagem de proteínas foi realizada com alíquotas da primeira diluição.

Para análise de açúcares totais, foi utilizado o método Fenol-sulfúrico (Dubois et al., 1956), com padrão galactose em concentrações de 20,40, 60 e $80 \mu \mathrm{g} / \mathrm{mL}$ para construção da curva padrão. Em um tubo de ensaio, misturou-se uma alíquota de $0,5 \mathrm{~mL}$ da amostra diluída com $0,5 \mathrm{~mL}$ de solução aquosa de fenol $5 \%$. Após, adicionaram-se a esta mistura 2,5 mL de ácido sulfúrico concentrado, agitando cuidadosamente. Aguardou-se 10 minutos, para então realizar a leitura em comprimento de onda de $490 \mathrm{~nm}$, no espectrofotômetro $\mathrm{DU}^{\circledR}-70^{8}$. Em presença de açúcares, a solução adquire coloração amarelo-alaranjada, variando a intensidade conforme a concentração dos açúcares.

Para análise de proteínas, utilizou-se o método Biureto, com padrão BSA em concentrações de 1,0;2,0; 3,0 e $5,0 \mathrm{mg} / \mathrm{mL}$ para construção da curva padrão. Em um tubo de ensaio, misturou-se uma alíquota de $2 \mathrm{~mL}$ da amostra diluída com $2 \mathrm{~mL}$ de solução de biureto. Aguardou-se 20 minutos, para então realizar a leitura em comprimento de onda de $540 \mathrm{~nm}$, no espectrofotômetro $\mathrm{DU}^{\circledR}-70^{8}$. Em presença de proteínas, a solução adquire coloração púrpura, variando a intensidade segundo a concentração das proteínas.

As amostras de muco bruto de cada grupo experimental foram liofilizadas primeiramente no Laboratório de Bioquímica da Faculdade de Ciências Farmacêuticas da USP de Ribeirão Preto, para as análises em espectroscópio de infravermelho, no Laboratório de Química Orgânica.

Parte das amostras liofilizadas previamente foi encaminhada ao Laboratório de Espectroscopia Molecular do Instituto de Química da USP de São Paulo e analisada em espectroscópio Raman FT-Raman Bruker - RFS 100/S, com resolução de $4 \mathrm{~cm}^{-1}$, laser $\mathrm{Nd}^{3+} / \mathrm{YAG}=1064 \mathrm{~nm}$, potência laser amostra $70 \mathrm{mWatts}$.

As análises de ganho de peso em função do tempo foram efetuadas por regressão, por meio do PROC REG (SAS, 1992), utilizando-se valor médio do peso dos animais de cada grupo experimental. Para as análises químicas, realizadas pelo PROC GLM do SAS, adotou-se o modelo que contempla os efeitos principais de espécie (Achatina fulica e Achatina monochromatica) e de ração (controle, centelha asiática, papaína e confrei), além da interação espécie $\times$ ração. Quando significativa, procedeu-se ao desdobramento para interação, para verificar o comportamento das espécies dentro de cada ração.

\section{Resultados e Discussão}

Os animais não mostraram rejeição ao alimento ofertado; porém, não se pode inferir sobre preferência alimentar, uma vez que houve diferença no ganho de peso médio para as diferentes rações estudadas. A ração adicionada de centelha asiática propiciou maior ganho de peso médio para Achatina fulica, resultado que não se repetiu para Achatina monochromatica, comprovando diferenças comportamentais decorrentes das rações ofertadas.

Observou-se maior ganho de peso médio nos grupos que receberam as rações controle e adicionadas de confrei para Achatina fulica, enquanto, para os grupos Achatina monochromatica, apenas o grupo controle apresentou maior ganho de peso.

A coloração dos mucos dos caracóis Achatina fulica alterou, mostrando-se mais clara nos animais que receberam a ração adicionada de papaína, esverdeada nos que receberam ração adicionada de confrei e amarelada no grupo controle e nos animais alimentados com ração adicionada 
de centelha. Observou-se maior viscosidade do muco dos animais submetidos à ração adicionada de papaína, bem como maior fragilidade em sua concha, que ficou quebradiça e extremamente fina. Os mucos dos caracóis Achatina monochromatica apresentaram cor mais acinzentada e menor viscosidade que os Achatina fulica e os Achatina fulica. Observou-se, claramente, produção de muco de caracóis Achatina monochromatica significativamente inferior (50\% menor) à dos caracóis Achatina fulica. A alteração na coloração dos mucos coletados de ambas as espécies, tanto do grupo controle (FC e MC) quanto dos demais que tiveram aditivos em sua ração (grupos $\mathrm{FCe}, \mathrm{FPa}$, FCo, MCe, MPa e MCo), pode indicar a absorção de elementos das plantas medicinais adicionadas à ração controle.

A média inicial de ganho de peso entre as duas espécies estudadas não diferiu (Tabela 2) significativamente e apresentou coeficientes de variação muito próximos, no período experimental (150 dias). Notou-se diferença quanto ao peso médio: na ração suplementada com centelha, houve ganho de $26,41 \%$ a mais em relação à ração controle, enquanto, na ração adicionada de confrei, o ganho foi de apenas 3,10\%. Já na ração suplementada com papaína, obteve-se 43,60\% a menos de ganho de peso médio. Portanto, a ração suplementada com centelha propiciou maior ganho de peso médio $(15,51 \mathrm{~g})$. Todas as rações adicionadas de plantas medicinais com princípio cicatrizante definido promoveram resposta ao tratamento da espécie Achatina fulica. As diferenças de ganho de peso foram significativas, segundo o teste $t$ de Student. As rações controle e suplementadas com papaína apresentaram desempenhos semelhantes e intermediários em relação àquela adicionada de centelha e a adicionada de confrei, os piores. Nos grupos experimentais Achatina monochromatica, observou-se que a resposta à suplementação da ração diferiu significativamente dos grupos Achatina fulica para o ganho de peso médio. Somente as rações controle e suplementada com centelha proporcionaram resposta significativa ao tratamento. Os animais submetidos à ração controle mostraram melhor desempenho que os alimentados com a ração adicionada de centelha, os quais, porém, apresentaram maior variação no ganho de peso médio por período experimental.

Tabela 2 - Estatística descritiva para o período experimental

\begin{tabular}{lccccc}
\hline Espécie & Média & $\begin{array}{c}\text { Desvio- } \\
\text { padrão }\end{array}$ \\
\hline Achatina fulica & 56,08 & 7,12 & 12,70 & 45,50 & 68,00 \\
$\begin{array}{l}\text { Achatina } \\
\text { monochromatica }\end{array}$ & 52,70 & 9,47 & 17,97 & 40,00 & 69,50 \\
\hline
\end{tabular}

Observou-se maior ganho de peso médio $(19,70 \mathrm{~g})$ para os animais que receberam a ração 1 (controle); no entanto, os alimentados com as rações 3 (adicionada de confrei) e 4 (adicionada de papaína) não apresentaram ganho de peso médio significativo ao longo do período experimental. Os animais que receberam a ração 2 (adicionada de centelha) apresentaram ganho de peso médio $15,08 \%$ inferior que os alimentados com a ração 1 (controle).

Quanto à análise da concentração de proteínas e açúcares dos grupos experimentais de Achatina fulica, após a realização das dosagens de açúcares totais e proteínas nos mucos de cada um dos grupos experimentais, foi observada variação significativa (Tabela 3 ).

Considerando que o grupo controle apresente valor de proteína equivalente a $100 \%$, nota-se que, em relação ao grupo controle (FC), o grupo FCe reduziu em $0,44 \%$ o teor de proteína, o grupo $\mathrm{FPa}$ em 1,12\% e o grupo FCo em $0,76 \%$. Em relação ao teor de açúcares totais, comparando-se ao grupo controle (grupo FC), o grupo FCe aumentou em $5,45 \%$ o teor de açúcares totais, o grupo FPa em 14,03\% e o grupo FCo em $9,53 \%$. Ao se comparar a variação da concentração de proteínas e açúcares totais nos mucos analisados da espécie Achatina monochromatica, observou-se que, em relação ao grupo controle (grupo MC), considerando que seu valor de proteína seja equivalente a 100\%, o grupo MCe aumentou em 3\% o teor de proteína, o grupo MPa em 2,35\% e o grupo MCo em 1,6\%. No entanto, o teor de açúcares totais, em relação ao controle (MC), foi reduzido em $30 \%$ pelo grupo $\mathrm{MCe}, 23,5 \%$ pelo grupo $\mathrm{MPa}$ e $16 \%$ pelo grupo MCo.

A análise de açúcares totais das espécies estudadas neste experimento mostrou resultados significativos para o efeito de interação espécie $(\mathrm{P}<0,01) \times$ ração $(\mathrm{P}<0,05)$. Não foram verificados resultados significativos $(\mathrm{P}>0,05)$ para os fatores principais. A espécie Achatina monochromatica mostrou teores de açúcares totais $(3,07 \mathrm{mg} / \mathrm{mL})$ significativamente superiores em relação à espécie Achatina fulica $(1,13 \mathrm{mg} / \mathrm{mL})(\mathrm{P}<0,01)$. As rações 1 (controle) e 3 (adicionada de confrei) obtiveram resultados significativos quanto ao teor de açúcares totais presente no muco, enquanto as rações 2 (adicionada de centelha) e 4 (adicionada de papaína) não mostraram diferenças significativas para $\mathrm{P}<0,01$. Não houve resultados significativos para a interação espécie $\times$ ração.

A análise de proteínas das espécies estudadas neste experimento indicou interação significativa $(\mathrm{P}<0,01)$ espécie $\times$ ração. $O$ desdobramento da interação foi realizado visando verificar o comportamento da espécie de caracol terrestre dentro de cada ração avaliada. A espécie 
Tabela 3 - Relação entre proteína e açúcares totais presentes no muco da espécie Achatina fulica (F) e Achatina monochromatica (M) nas diferentes rações ofertadas

\begin{tabular}{|c|c|c|c|c|c|c|c|c|}
\hline \multirow[t]{2}{*}{ Grupo } & FC & $\mathrm{FCe}$ & $\mathrm{FPa}$ & FCo & $\mathrm{MC}$ & $\mathrm{MCe}$ & $\mathrm{MPa}$ & MCo \\
\hline & {$[\quad] \%$} & {$[\quad] \%$} & {$[\quad] \%$} & {$[\quad] \%$} & {$[\quad] \%$} & {$[\quad] \%$} & {$[\quad] \%$} & {$[\quad] \%$} \\
\hline Açúcar total & 7,34 & 7,74 & 8,37 & 8,04 & 9,09 & 6,37 & 6,95 & 7,64 \\
\hline Proteína & 92,66 & 92,26 & 91,63 & 91,96 & 90,91 & 93,63 & 93,05 & 92,60 \\
\hline
\end{tabular}

[ ] \% = proporção da concentração de proteínas e açúcares totais em percentagem.

Grupos: FC e MC (ração controle), FCe e MCe (ração controle adicionada de centelha), FPa e MPa (ração controle adicionada de papaína) e, FCo e MCo (ração controle adicionada de confrei).

Achatina monochromatica apresentou resultados significativos quanto ao teor de proteínas presente no muco, enquanto a espécie Achatina fulica não mostrou essas diferenças significativas $(\mathrm{P}<0,01)$. Observou-se interação espécie × ração para a espécie Achatina monochromatica, que obteve resposta significativa com as quatro diferentes rações avaliadas em comparação à Achatina fulica.

As espectroscopias em infravermelho e Raman foram utilizadas para detectar características de bandas de absorção de infravermelho de carboidratos e proteínas. Pequenas diferenças são reportadas entre os grupos experimentais, demonstrando que a espectroscopia pode ser potencialmente utilizada para a identificação destes grupos. O espectro de espalhamento Raman e o espectro de absorção infravermelho de determinada espécie são bem semelhantes; há, porém, diferenças suficientes entre os tipos de grupos ativos no infravermelho e no Raman para tornar essas técnicas complementares, em vez de competitivas. Importante vantagem dos espectros Raman sobre os de infravermelho está no fato de que a água não causa interferência. De fato, os espectros Raman são semelhantes aos de infravermelho no sentido de possuírem regiões úteis para detecção de grupos funcionais e regiões características de impressão digital que permitem a identificação de compostos específicos (Skoog et al., 2002).

Em todos os grupos de caracóis analisados, houve um perfil de bandas principais que se iniciou em torno de 1.651 e $1.655 \mathrm{~cm}^{-1}$. Os picos indicaram a presença de ligações do tipo amida que ocorrem nos núcleos protéicos de GAGs e moléculas proteoglicanas, como lectina (Skingsley et al., 2000). Faixas em torno de $1.450 \mathrm{~cm}^{-1}\left(\mathrm{CH}_{2}\right)$ e $1.380 \mathrm{~cm}^{-1}$ $\left(\mathrm{CH}_{3}\right)$ representam cadeias de carbono de proteínas, carboidratos e possíveis lipídeos (Nakamoto \& Czernuszewicz, 1993). As bandas entre 1.643 e $1.543 \mathrm{~cm}^{-1}$ são características de amida I e amida II, respectivamente. No intervalo de 1.736 a $1.230 \mathrm{~cm}^{-1}$, encontram-se também alguns açúcares (bandas características de ésteres). Em bandas entre $774 \mathrm{~cm}^{-1} \mathrm{e} 930 \mathrm{~cm}^{-1}$, têm-se os açúcares (como alfa e beta piranose) e polissacarídeos (Lindon, 2000). Os resultados dos espectros de infravermelho foram analisados em cada grupo experimental, no qual se tomou por referência o grupo controle (FC) da espécie Achatina fulica. O perfil espectral indicou uma quantidade relativa de moléculas ionizadas e hidratadas, observando-se pequena diferença na proporção entre os grupos experimentais. Entre $600 \mathrm{e} 1.500 \mathrm{~cm}^{-1}$, há uma gama de faixas relacionando cadeias carbônicas de núcleos protéicos $\left(\mathrm{CH}_{2}, \mathrm{CH}_{3}\right)$ e composição e estado de ionização de cadeias laterais de aminoácidos e de açúcares $\left(\mathrm{COOH}, \mathrm{COO}^{-}\right)$, presença de glicoproteínas, amidas 3 de colágeno, traços de lipídeos.

Comparando os espectros dos mucos Achatina fulica e Achatina monochromatica (Figuras 1 e 2), observou-se que as variações espectrais para as faixas referentes aos grupos de glicoproteínas e carboidratos são mínimas. A análise dos espectros poderia ser feita pela intensidade, largura ou forma das bandas apresentadas. Os espectros dos mucos estudados apresentaram-se muito semelhantes, de forma que se procedeu à análise pela intensidade das bandas espectrais nos valores mínimos de transmissão, referentes aos grupos de carboidratos e de proteínas, onde as bandas da região de $3.400 \mathrm{~cm}^{-1}$ são características de estiramento de moléculas $\mathrm{OH}$ e, conseqüentemente, a região onde ocorre maior contribuição dos carboidratos presentes no muco de caracóis terrestres estudados. As bandas da região de $1.650 \mathrm{~cm}^{-1}$, por sua vez, são características da presença de amida I, o que remete a uma região de maior contribuição de proteínas existentes no muco de caracóis terrestres estudados.

Os espectros das amostras analisadas foram obtidos na região de 1.800 a $1.200 \mathrm{~cm}^{-1}$, pois dentro desta faixa podem-se analisar os espectros referentes às proteínas e aos carboidratos presentes na amostra em questão. Em todos os grupos analisados, houve um perfil de bandas principais nas regiões entre 1.700 e $1.600 \mathrm{~cm}^{-1}$ e $1.400 \mathrm{e}$ $1.300 \mathrm{~cm}^{-1}$, referentes aos grupos protéicos e de açúcares (carboidratos), respectivamente. Os picos na região de $1.600 \mathrm{a} 1.700 \mathrm{~cm}^{-1}$ indicam a presença de ligações do tipo amida que ocorrem nos núcleos protéicos de GAGs e moléculas proteoglicanas (Skingsley et al., 2000). Os resultados dos espectros Raman foram analisados para 


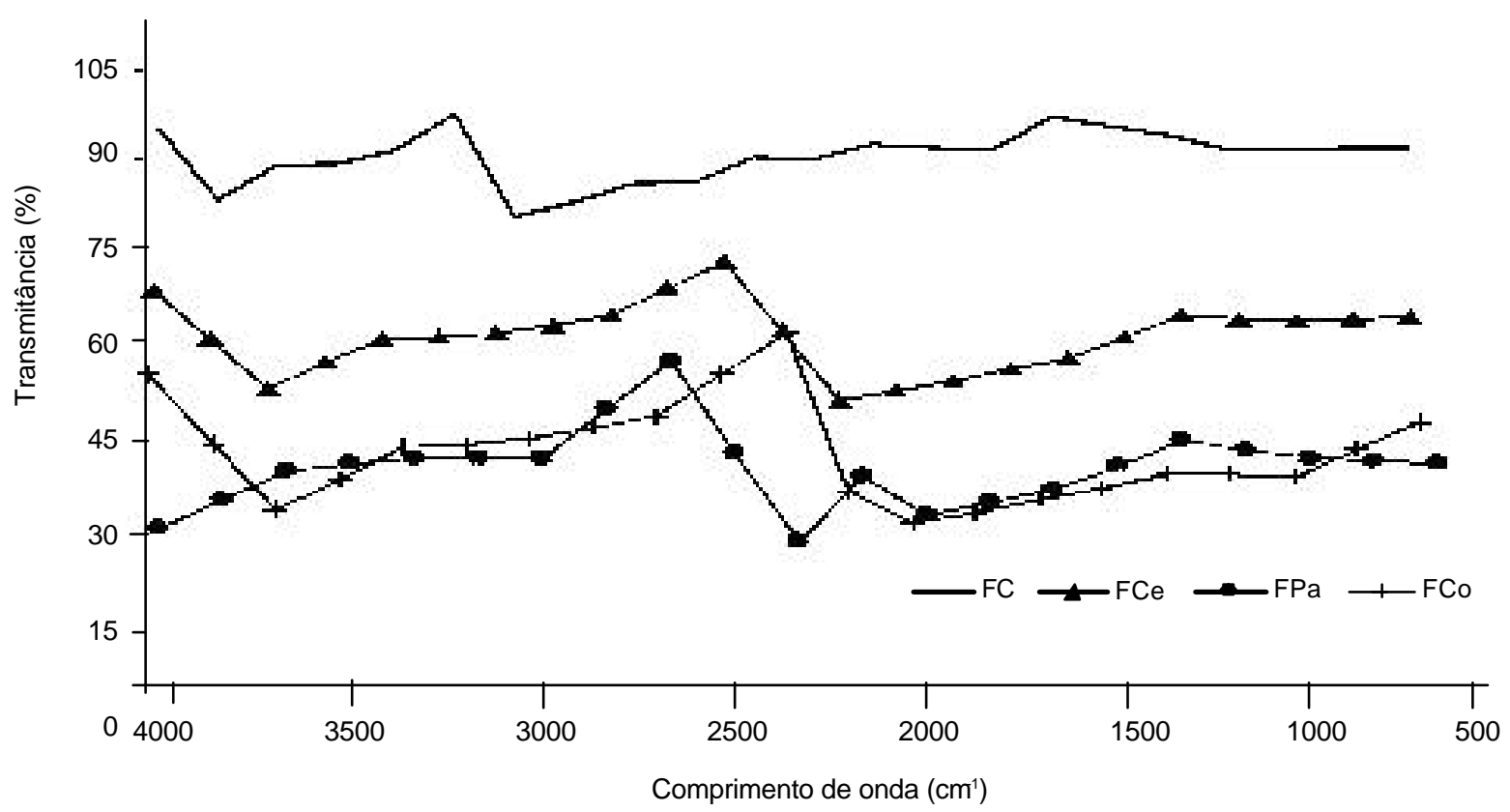

Figura 1 - Espectros das análises realizadas em infravermelho nos grupos experimentais FC, FCe, FPa e FCo para o molusco Achatina fulica

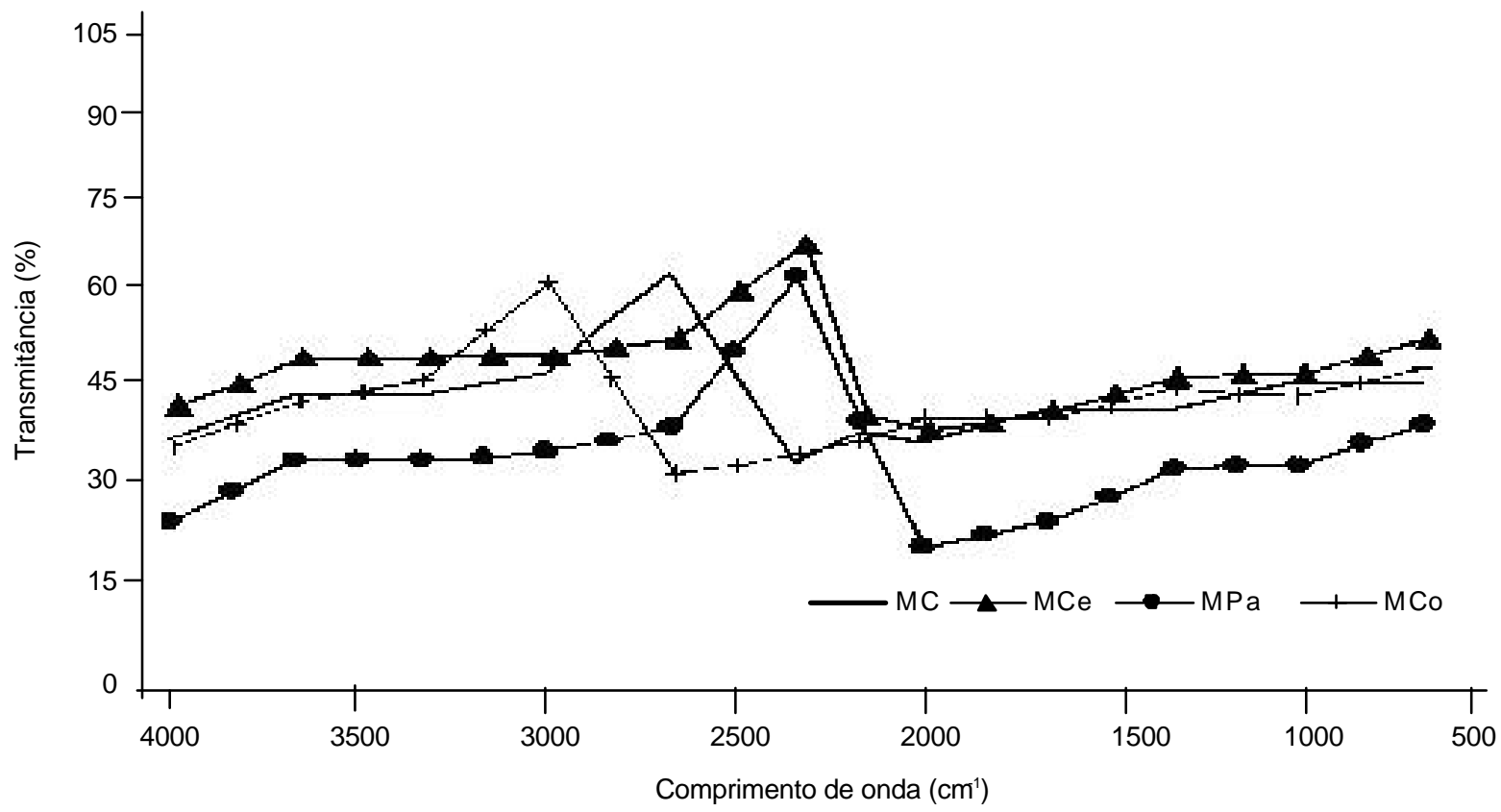

Figura 2 - Espectros das análises realizadas em infravermelho nos grupos experimentais MC, MCe, MPa e MCo para o molusco Achatina monochromatica

cada grupo experimental, onde se tomou por referência o grupo controle da espécie Achatina fulica (FC) e, posteriormente, o grupo controle da espécie Achatina monochromatica (MC). As análises realizadas por espectroscopia Raman atuaram como um material comple - mentar aos resultados obtidos por espectroscopia em infravermelho, uma vez que estas duas técnicas se completam e os resultados obtidos corroboram os observados com a espectroscopia em infravermelho e, conseqüentemente, as análises colorimétricas. A análise dos espectros 
foi realizada por meio da intensidade das bandas apresentadas, em razão da semelhança entre eles, analisando as bandas em seus valores máximos de transmissão, referentes aos grupos de proteínas e carboidratos, em que as bandas da região de 1.600 e $1.700 \mathrm{~cm}^{-1}$ são características da presença de grupamentos amida, remetendo a uma região de maior contribuição de proteínas existentes no muco de caracóis terrestres estudados. As bandas na região de 1.400 e $1.300 \mathrm{~cm}^{-1}$ referem-se aos grupos de ligações carbonooxigênio (C-O) características dos açúcares e, conseqüentemente, remetem à maior contribuição dos carboidratos presentes no muco de caracóis terrestres estudados.

Os espectros Raman dos mucos Achatina fulica e Achatina monochromatica possuem variaçõesespectrais

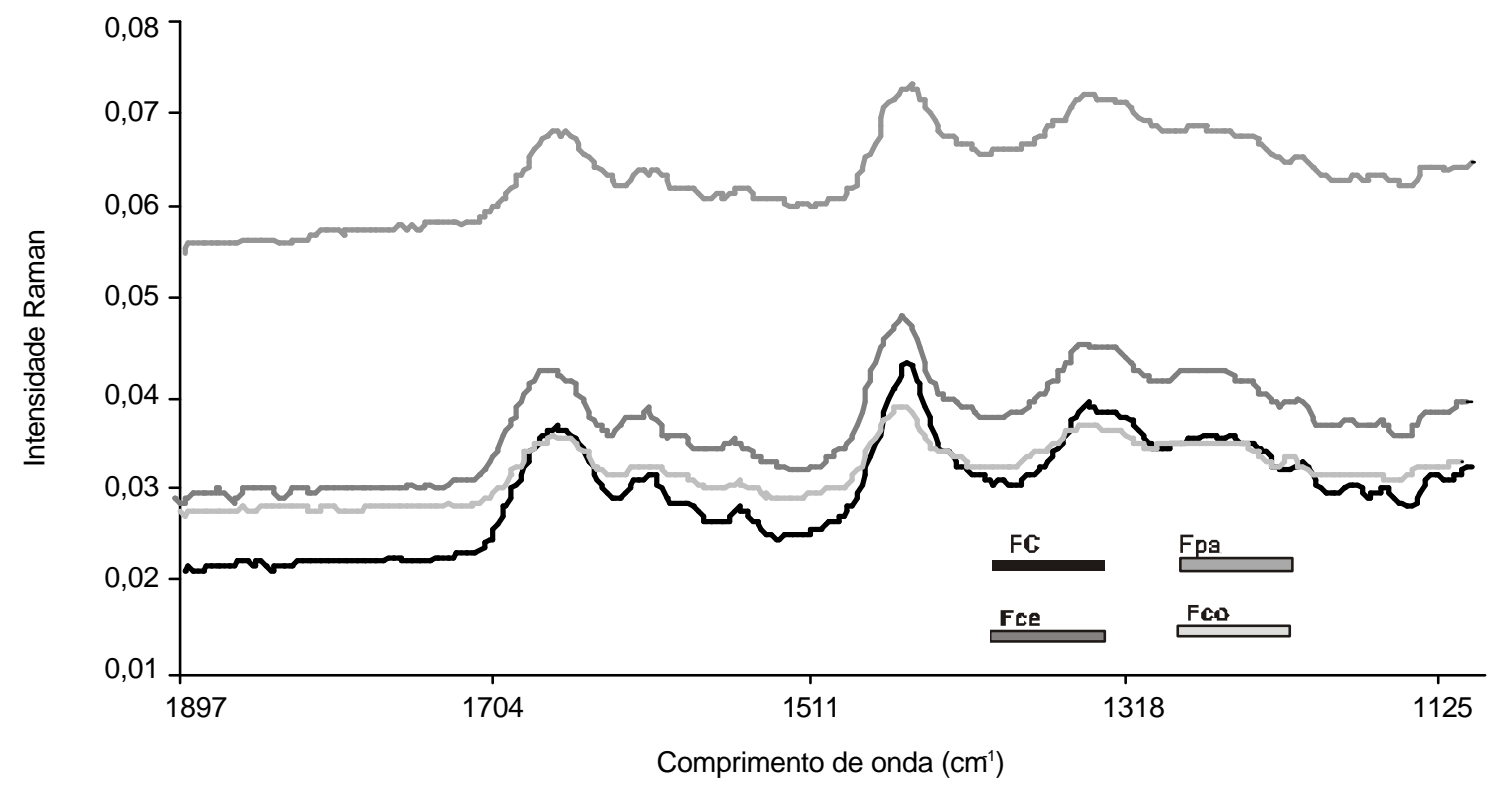

Figura 3 - Espectros Raman das análises realizadas nos grupos experimentais FC, FCe, FPa e FCo de Achatina fulica

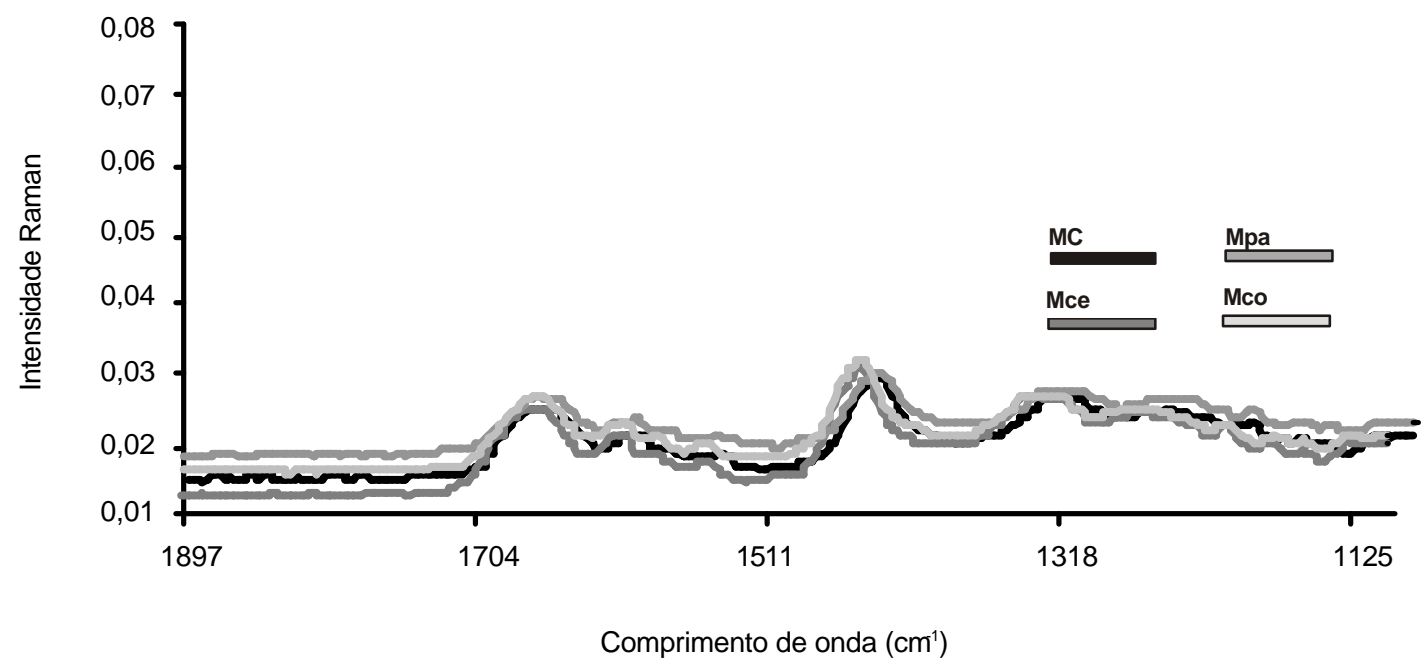

Figura 4 - Espectros Raman das análises realizadas nos grupos experimentais MC, MCe, MPa e MCo de Achatina monochromatica. 
muito semelhantes para as faixas referentes aos grupos de proteínas e carboidratos, 1.700 e $1.600 \mathrm{~cm}^{-1}$ e 1.300 e 1.400 , respectivamente (Figuras 3 e 4). Apesar da diferença no início da leitura do espectro do grupo alimentado com a ração adicionada de papaína (FPa), pertencente à espécie Achatina fulica, as variações presentes no espectro são semelhantes às dos outros grupos analisados.

A partir das análises em espectroscopia de infravermelho e Raman, observou-se que as relações proteína/carboidrato para infravermelho e carboidrato/proteína para Raman, comparando-se o grupo controle de ambos os gêneros (grupos FC - Achatina fulica e MC - Achatina monochromatica) com os tratamentos Achatina fulica $\mathrm{e}$ Achatina monochromatica (FCe, FPa, FCo e MCe, MPa, $\mathrm{MCo}$, respectivamente), apresentaram valores maiores e menores para as espécies, respectivamente, o que indica maior contribuição de açúcares para o primeiro (Achatina fulica) e de proteínas para o segundo (Achatina monochromatica). Estes resultados corroboram os obtidos nos testes colorimétricos dos mucos analisados, ou seja, entre as devidas proporções de açúcares e proteínas encontrados nos mucos em questão, os grupos pertencentes à espécie Achatina fulica apresentaram redução significativa quanto ao teor de proteínas e aumento no teor de açúcares totais, enquanto aqueles pertencentes à espécie Achatina monochromatica, redução no teor de açúcares totais e aumento no teor de proteínas.

\section{Conclusões}

Com a adição de plantas medicinais com finalidades cicatrizantes comprovadas, a ração base oferecida aos caracóis Achatina sp indicou a contribuição destas plantas na composição do muco dos caracóis, possibilitando a implementação e contribuição a estudos de avaliação do reparo tecidual em seus variados estádios de cicatrização. As metodologias empregadas mostraram-se sensíveis e apropriadas aos objetivos propostos neste estudo.

O estudo da composição do muco de caracóis, parte de pesquisas complexas e ainda não totalmente compreendidas quanto ao processo cicatricial, impulsiona novos estudos dos profissionais que atuam em saúde animal e humana, constituindo-se o catalisador para posteriores estudos e pesquisas.

\section{Literatura Citada}

ASSOCIATION OF OFFICIAL ANALYTICAL CHEMISTS- AOAC. Official methods of analysis. 16.ed. Washington, D.C: 1995. $1141 \mathrm{p}$.

DUBOIS, M.; GILLES, K.A.; HAMILTON, J.K. et al. Colorimetric method for determination of sugars and related substances. Analytical Chemistry, v.28, 1956, p.350-356.

IGUCHI, S.M.M.; AIKAWA, T.; MATSUMOTO, J.J. Antibacterial activity of snail mucus mucin. Comparative Biochemistry and Physiology, v.72A, n.3, 1982, p.571-574.

LINDON, J.C. Encyclopedia of spectroscopy and spectrometry. San Diego: Academic Press, 2000. p.1576-1583.

MARTINS, M.F.; PACHECO, P.; SÍRIO, O. et al. Ação bactericida do muco podal do escargot Achatina fulica. In: CONGRESSO BRASILEIRO DE MEDICINA VETERINÁRIA, 29., 2003, Manaus. Anais... Manaus: Sociedade Brasileira de Medicina Veterinária, 2003. v.1, p.121.

NAKAMOTO, K.; CZERNUSZEWICZ, R.S. Infrared spectroscopy. In: RIORDAN, J.F.; VALLEE, B.L. (Eds.) Methods in enzymology. New York: Academic Press, 1993. v.226, p.259-289.

PACHECO, P.; MARTINS, M.F. Desempenho ponderal do escargot Achatina $s p$ frente a diferentes formulações de ração. In CONGRESSO BRASILEIRO MEDICINA VETERINÁRIA, 14. 1996, Goiânia. Anais... Goiânia: 1996, v.8. p.184.

STATISTICAL ANALYSIS SYSTEM - SAS. User's guide. release 6.08 (software), 1992. (CD-ROM).

SÍRIO, O.J. Verificação da potencialização do efeito cicatrizante do muco de caracóis do gênero Achatina promovida por ração à base de confrei. Pirassununga: Universidade de São Paulo, 2005. 87p. Dissertação (Mestrado em Nutrição Animal) Universidade de São Paulo, 2005.

SKINGSLEY, D.R.; WHITE, A.J.; WEATON, A. Analysis of pulmonate mucus by infrared spectroscopy. Journal Molluscan Stududies, v.66, p.363-371, 2001.

SKOOG, D.A.; HOLleR, F.J.; NIEMAN, T.A. Princípios da análise instrumental. 5.ed. São Paulo: Bookman, 2002. $836 \mathrm{p}$. 